\title{
O COTIDIANO DE PROFESSORES E ALUNOS NAS AULAS DE EDUCAÇÃO FÍSICA: REVISÃO TEÓRICA
}

\author{
THE DAILY SCHOOL OF TEACHERS AND STUDENTS IN \\ PHYSICAL EDUCATION CLASSES: THEORETICAL REVIEW

\section{LA VIDA DIARIA DE PROFESORES Y ALUMNOS EN LAS CLASES DE EDUCACIÓN FÍSICA: REVISIÓN TEÓRICA}

Adalberto dos Santos Souza ${ }^{1}$ CinTHIA LOPES DA SILVA ${ }^{\text {II }}$

${ }^{\mathrm{I}}$ Universidade Federal de São Paulo (UNIFESP), Guarulhos/SP-Brasil "I Universidade Metodista de Piracicaba (UNIMEP), Piracicaba/SP- Brasil

RESUMo Este trabalho tem como objetivo realizar reflexões sobre o cotidiano escolar de professores e alunos nas aulas de Educação Física (EF), considerando a perspectiva do conceito de "cotidiano" de Michel de Certeau. Nas aulas de EF, o conhecimento escolarizado é muitas vezes tratado de um modo impositivo, e ao que tudo indica isso ocorre pelo fato da EF ser uma disciplina que lida com questões relacionadas ao corpo e às práticas corporais, de modo que é frequente os professores de EF desconsiderarem os aspectos simbólicos que os alunos atribuem às aulas e aos seus conteúdos vivenciados. Como procedimentos metodológicos foi realizada revisão de literatura, centrada nas aulas de EF escolar e nos estudos do cotidiano na escola, caracterizando este trabalho como qualitativo. Foi feito um levantamento bibliográfico para a seleção de textos que apresentassem dados de pesquisa de campo a respeito dos significados das aulas de EF e o trabalho docente. Para a busca, utilizou-se o site google acadêmico e os termos chave: "significados das aulas de Educação Física" e "trabalho docente", sem a combinação entre si. Chegou-se à conclusão que o cotidiano de professores e alunos na escola é construído e reconstruído de forma dialética. É justamente o contínuo processo de ressignificação das aulas de EF que pode gerar a resistência à tradição de tais aulas, assim como minimizar problemas que afastam os alunos das aulas de EF e da escola.

Palavras-chave: Educação; Educação Física; Cotidiano; Cultura. 
ABSTRACT This work is aimed at reflecting upon on the daily life of teachers and students in Physical Education (PE) classes, considering the perspective of Michel de Certeau's concept of "daily life". In PE classes the school knowledge is often treated in an imposing way, and it seems that this is due to the fact of the PE to be a subject which deals with matters related to the body and bodily practices. Therefore, PE teachers usually disregard the symbolic aspects that students impute to class and to contents they have experienced. Revision of literature focused on Physical Education classes and daily studies at school were used as the methodology procedures, thus characterizing this work as qualitative. A bibliographic survey was done in order to select texts which presented field research data about the meanings of Physical Education classes and teacher's work. The words used in the search on academic google and the key words were: "meanings of Physical Education classes" and "teacher's work", without combining each other. The conclusion is that the daily school of teachers and students is constructed and reconstructed in a dialectical way. The continuous process of resignification of Physical Education classes is precisely what can generate resistance to the tradition of such classes, as well as minimizing problems which alienate students in Physical Education classes and in the school as a whole.

Keywords: Education; Physical Education; Everyday Life; Culture.

RESUMen Este trabajo tiene como objetivo realizar reflexiones de la vida diaria de profesores y alumnos en las clases de Educación Física (EF), considerando la perspectiva del concepto de "vida diaria" de Michel de Certeau. En las clases de EF el conocimiento escolarizado es muchas veces tratado de un modo impositivo y al que todo indica eso ocurre por lo facto de la EF ser una disciplina que lidia con cuestiones relacionadas con el cuerpo y las prácticas corporales, de modo que son frecuentes los profesores de EF desconsideraren los aspectos simbólicos que los alumnos atribuyen a las clases y a los sus contenidos vivenciados. Como parte de la metodología fue realizada revisión de literatura, centrada en las clases de EF escolar y en los estudios de la vida diaria en la escuela, caracterizando este trabajo como cualitativo. Fue hecho levantamiento bibliográfico para la selección de textos que presentasen datos de investigación de campo sobre los significados de las clases de EF y trabajo docente. Para la búsqueda fue utilizado el site google acadêmico y los términos clave: "significados de las clases de Educación Física" y "trabajo docente", sin la combinación entre si. La conclusión es que la vida diaria de profesores y alumnos en la escuela es construida y reconstruida de forma dialéctica. Es justamente el contínuo proceso de resignificación de las clases de EF que puede generar una resistencia a la tradición de tales clases, así como minimizar problemas que apartan los alumnos de las clases de EF y de la escuela.

Palabras clave: Educación; Educación Física; Vida diaria; Cultura.

\section{INTRODUÇÃO}

Discorrer sobre o tema do cotidiano tornou-se algo frequente nas pesquisas na área das Ciências Humanas, em especial na Educação e, como consequência, nos textos aca- 
dêmicos da atualidade. A predominância do tema tem evidenciado um interesse crescente por parte dos pesquisadores, pelo que podemos chamar de questões do dia a dia. Segundo Chizzotti (2010, p. 87-88), as questões do dia a dia são as que "compõem os acontecimentos diários da vida e os significados que as pessoas vão construindo, nos seus hábitos, nos rituais em que celebram no recinto doméstico ou da sala de aula".

A análise do que ocorre cotidianamente nas conversas, práticas rotineiras, gestos, rituais e como isso é construído socialmente têm sido um dos objetos mais importantes para a compreensão das relações sociais. A escola e os acontecimentos que permeiam o seu cotidiano se dão a partir dessas relações, ou dito de outro modo, elas são fruto das relações sociais.

Essa nova forma de observar o cotidiano escolar no que diz respeito às questões do dia a dia nos levou a investigar uma questão que é cada vez mais presente, tanto nas discussões sobre o papel do professor na escola, como na relação da escola com o mundo que a cerca, qual seja, como os professores de Educação Física (EF) compreendem suas aulas e, a partir disso, como é construído o seu cotidiano com os alunos.

Falar sobre o cotidiano das aulas de $\mathrm{EF}^{1}$ impõe, necessariamente, falar a respeito dos atores sociais que compõem esse ambiente, uma vez que a instituição escolar é um todo complexo que se completa a partir das relações estabelecidas cotidianamente entre eles.

Tradicionalmente, a EF tem se constituído como uma área do conhecimento com predomínio das Ciências Biológicas. Assim, quando há uma direção pedagógica nessas aulas, as questões relacionadas ao corpo e às práticas corporais são tratadas, com frequência, de modo impositivo. O professor se apoia em um modelo tradicional de aula e considera que a finalidade de sua aula é desenvolver as aptidões físicas dos alunos - suas capacidades físicas e técnicas ao invés de considerar os significados das ações dos alunos nos jogos, nas ginásticas, nas danças, nas lutas, nos esportes, essa é uma crítica que foi feita pelo clássico livro Metodologia do Ensino de Educação Física (COLETIVO DE AUTORES, 1992), uma das primeiras obras da área da Educação Física a discutir a noção de "cultura corporal". Fazemos referência aqui a essa obra pela importância histórica da mesma, embora temos apoio nos princípios da EF Plural, outra teoria da área da EF, por ser mais próxima em termos teóricos dos estudos de Michel de Certeau, mais adiante voltaremos a mencionar a EF Plural. Assim, conteúdos como o esporte são predominantes nas aulas, muitas vezes o que é proposto tem características próximas de um treinamento esportivo e as aulas são marcadas pelo aspecto da competição muitas vezes exacerbada. A ação do professor de EF é de solicitar aos alunos que façam um conjunto de movimentos corporais, a fim de melhorar suas habilidades motoras, sua flexibilidade, força e velocidade. Um segundo tipo de aula é aquela que tem como característica o uso de jogos e brincadeiras como um meio dos alunos desenvolverem seu aspecto cognitivo, de modo que possam atingir certo nível de autonomia (FREIRE e SANTANA, 2007),

\footnotetext{
Aqui se entende que as aulas de Educação Física são uma prática pedagógica e a Educação Física é uma área do conhecimento que tem como especificidade a prática pedagógica que lida com os conhecimentos dos jogos, danças, lutas, esportes, ginásticas etc., tendo como base Bracht (2000). Valter Bracht é um autor que se aproxima em termos teóricos de Jocimar Daolio, de acordo com análise feita por esse segundo, em seu livro "Educação Física e o conceito de cultura" (DAOLIO, 2004) e é em Daolio (1995) que temos melhor definido os princípios da EF Plural, que a área entendeu como sendo uma das teorias da EF, por isso nossa menção aqui ao Bracht (2000) e Daolio (1995, 2004).
} 
essa referência de aula originada da abordagem interacionista construtivista recebe críticas na área por não considerar a especificidade das aulas de Educação Física o ensino do jogo, da ginástica, da dança, da luta, do esporte com um fim em si mesmo, já que o único conteúdo tratado nas aulas são jogos e brincadeiras e mesmo assim como meio de aprendizagem. Desse modo, os alunos em uma mesma escola podem passar anos de sua vida escolar realizando atividades semelhantes nas aulas de EF. Além dessa questão, há também o caso do professor de EF que deixa os alunos fazerem o que querem na aula, sem imprimir uma direção pedagógica clara. $\mathrm{O}$ que se assemelha a uma não aula.

Os tipos de aulas já descritos podem contribuir para a evasão dos alunos na escola ou justificar o não interesse de muitos alunos nas aulas de EF. Tenório e Silva (2015) reforçam essa ideia, afirmando que nas aulas de EF, entre os alunos que estão na Educação Básica, muitos não participam das aulas por motivos variados que envolvem questões de ordem didático-metodológicas e de organização curricular, ou seja, o modo como a escola trata cotidianamente o conhecimento influencia a forma como os alunos a veem.

Em virtude dessas questões, o propósito deste artigo é realizar algumas reflexões sobre o cotidiano escolar de professores e alunos nas aulas de EF, considerando a perspectiva do conceito de "cotidiano" de Michel de Certeau. A relação entre esses sujeitos é expressão do modo como a aula de EF é construída. Tais sujeitos inventam a todo o momento certo modo de convívio e de agir que aqui observamos como "artes de fazer", sendo que os estudos do cotidiano poderão fornecer elementos para se pensar novas táticas de resistência desse lugar "habitado", "praticado" e "vivido" por professores e alunos que é a escola (CERTEAU, 2011b).

\section{Procedimentos metodológicos}

Foi realizado levantamento bibliográfico, centrado nas aulas de EF escolar e nos estudos do cotidiano na escola, caracterizando esse trabalho como qualitativo. Foi feito levantamento bibliográfico para a seleção de textos que apresentassem dados de pesquisa de campo sobre os significados das aulas de EF e trabalho docente. Para a busca, utilizou-se o site google acadêmico e os termos chave: "significados das aulas de Educação Física" e "trabalho docente", sem a combinação entre si. O período da busca foi de novembro de 2016 a março de 2017 (esse período foi selecionado por conveniência e exequibilidade, pois abrangeu os estudos de pós-doutorado de um dos autores e foi durante tais estudos que essa produção pôde ser discutida e preparada). Foram incluídos textos específicos que tratavam de investigações de campo a respeito das aulas de EF e que podiam ser referência para as reflexões aqui desenvolvidas. O levantamento bibliográfico foi ampliado, incluindo-se textos que são trabalhados nos grupos de pesquisa dos autores. Foram excluídos os textos em que o título ou o resumo não indicavam contribuições para a discussão aqui proposta acerca do cotidiano de professores e alunos em aulas de EF escolar. 


\section{RESULTADOS E DISCUSSÃo}

\section{Os Estudos do Cotidiano e os Significados Atribuídos às Aulas de Edu- cação Física na Escola}

Os primeiros contatos com as obras de Michel de Certeau nos fizeram refletir sobre alguns pontos importantes, entre eles os conceitos de práticas cotidianas, as discussões sobre o "lugar praticado", bem como, as táticas não calculadas que se relacionam com as "artes de fazer".

Tal movimento possibilitou uma imersão nos estudos sobre o cotidiano escolar, ${ }^{2}$ considerando a perspectiva de análise certeauniana sobre as relações de poder e de "burlas" instauradas em algumas práticas escolares. É em virtude disso que as representações de professores e alunos, as formas como ambos interpretam as políticas educacionais e as suas maneiras de fazer cotidianamente a escola estão no centro desta discussão.

O aprendizado possibilitado pelas leituras de Certeau (2011a) mostrou, entre outras coisas, que a compreensão do cotidiano nos dá muito mais pistas para a compreensão da relação professor e aluno do que imaginamos. Na compreensão de Certeau (2011a, p. 31), “[...] o cotidiano é aquilo que nos prende intimamente, a partir do interior [...]. É uma história a caminho de nós mesmos, quase em retirada, às vezes velada". Desse modo, dialogar sobre um tema em que pode haver recusa ou resistência na escola por parte de dirigentes e professores é, portanto, para esse autor, instigante e ao mesmo tempo desafiador.

As criações e as reinvenções cotidianas da escola, e por que não dizer de outros lugares, vistas a partir da perspectiva certeauniana, nos fazem pensar numa inversão de perspectiva, em uma mudança de atenção. Com isso, pode-se encontrar sentidos nas relações que envolvam professores e alunos, nesse caso, os de EF, de modo a nos revelar como são construídos e legitimados os saberes e valores que permeiam suas práticas escolares.

A construção desses saberes e valores para os professores e alunos não é dada pronta, acabada, eles são elaborados a partir de uma construção cotidiana da vida humana, do se fazer humano constantemente. Embora isso não seja percebido pela maioria desses sujeitos, é um caminho cada vez mais necessário para a compreensão desse mundo que se quer fazer homogeneizado.

As aulas de EF são construídas no cotidiano de professores e alunos, dialogadas por vários atores que compartilham desse lugar vivido que é a escola. Assim, o cotidiano de professores e alunos é mediado pelo conjunto de significados atribuídos às aulas de EF pela direção e coordenação da escola, funcionários da portaria, cozinha, limpeza, pais e mães de alunos, e, por fim, pelos próprios professores e alunos. Alguns dados de pesquisa sobre estudos desses significados atribuídos a tais aulas são apontados por Betti e Liz (2003), Silva (2018), Wittizorecki e Molina Neto (2005) e Tenório e Silva (2015).

Temos como exemplo o estudo realizado por Betti e Liz (2003, p.141), com meninas do Ensino Fundamental de escolas públicas e particulares do município de Lençóis Paulista/SP, no qual obtiveram os seguintes resultados:

\footnotetext{
2 Ainda que os estudos de Certeau (2011a, 2011b) não tenham privilegiado as discussões sobre a instituição escolar, foram as aproximações com suas ideias que possibilitaram algumas das reflexões colocadas aqui.
} 
[...] 1 - A Educação Física é a disciplina de que as escolares mais gostam, mas não é considerada muito importante, quer dizer, fazem distinção entre o prazer e a satisfação propiciadas pelas aulas de Educação Física, e a importância que atribuem a outras disciplinas, em especial Matemática e Português. 2 - A Educação Física é fortemente associada pelas escolares ao esporte. 3 - Os benefícios percebidos pelas escolares como decorrentes da Educação Física giram prioritariamente em torno do desenvolvimento corporal.

Nota-se, na citação, que as meninas entrevistadas gostam das aulas de EF, mas esse gostar se relaciona a questões como o prazer e a satisfação propiciadas pelas aulas, não colocam a EF no mesmo status de disciplinas que têm conteúdos claramente definidos a se ensinar, como é o caso do Português e da Matemática. Os resultados também apontam para uma EF que se centra na tradição dessa área ao se referirem que a EF está fortemente associada ao esporte e ao desenvolvimento corporal.

Tenório e Silva (2015, p. 42) realizaram uma investigação com alunos (meninas e meninos) de uma escola pública do Estado de Mato Grosso e identificaram por que tais alunos não têm interesse nas aulas de EF na escola:

a) O modelo das aulas tradicional trouxe à tona percepções dos entrevistados em relação aos conteúdos ministrados desde o primário e podem ter trazido consequências para sua não participação nas aulas, sendo aquele aluno que já se desmotivava no primário ou a partir do $6^{\circ}$ ano por perceber as aulas como sempre as mesmas, além disso havia o fator da exclusão dos alunos menos habilidosos pelos demais colegas de turma; b) Eles falaram que a educação física significa pouco ou quase nada para eles, além de não conseguir expor o que a matéria ensina, explicitando o fato de ser uma matéria com pouca relevância para sua formação humana; c) $\mathrm{O}$ vôlei e o futsal, embora sejam conteúdos predominantes nas aulas, são citados pelos entrevistados como práticas corporais que se apresentaram de forma excludentes no ambiente educacional, constituindo um dilema a ser superado; d) Os alunos entrevistados atribuíram grande importância a presença de amigos durante as atividades, ou seja, a amizade e o espírito acolhedor, são dimensões do comportamento que aproximam os alunos das práticas corporais. No entanto, a decepção em algum momento, com atitudes excludentes, foi o motivo principal por afastá-los das aulas.

Assim, considerar os significados atribuídos às aulas de EF é olhar para os aspectos simbólicos que são construídos no cotidiano na escola.

Wittizorecki e Molina Neto (2005, p. 62) realizaram um estudo com professores de EF de escola pública da cidade de Porto Alegre/RS e um dos dilemas dos professores foi “[...] os desafios que os professores percebem em seu cotidiano. Quanto às inquietações, podem ser compreendidas como as preocupações, as provocações que mobilizam os professores na construção de suas estratégias e saberes". Na fala de um dos entrevistados da pesquisa, fica clara a preocupação em construir "[...] uma prática pedagógica alicerçada na produção de aprendizagens significativas e, portanto, de redimensionar tanto o conhecimento de que trata a própria disciplina, como o trabalho que realizam". Esse entrevistado sinaliza para a necessidade de superar o modelo tradicional de ensino e apresenta como saída proporcionar 
aos alunos que vivenciem situações lúdicas que possam levá-los à mudança de comportamento em nível afetivo.

Nessa pesquisa, é possível identificar os dilemas que os professores enfrentam em seu trabalho docente que muitas vezes envolve a questão da construção do currículo e de lidar de alguma maneira com documentos governamentais voltados às aulas de EF que podem determinar como a aula deve ser. Ainda aparece na fala dos entrevistados a necessidade de proporcionar aos alunos aprendizagens significativas, indicando a necessidade de superar o modelo tradicional de aulas. No entanto, o argumento utilizado para isso é a inclusão nas aulas de vivências de situações lúdicas, de modo a gerar mudanças de comportamento nos alunos em nível afetivo. Nota-se aí a preocupação não tanto com a produção de novos saberes, centrada no desenvolvimento de conteúdos da EF, mas das aulas serem um meio para outras finalidades, como a mudança de comportamento por parte dos alunos.

A leitura sobre o que ocorre na escola deve ser permeada pela compreensão dos mais diversos fatores que circunscrevem esse ambiente, que é ao mesmo tempo tão complexo como rico de significados. Para tal análise, devemos levar em consideração que ele é constituído, como afirma Dayrell (1996), por "um conjunto de tempos e espaços ritualizados e, que em cada situação, há uma dimensão simbólica, que se expressa nos gestos e posturas acompanhados de sentimentos" (p. 150). Nesse sentido, as pesquisas sobre o cotidiano escolar necessitam captar as artes de fazer, as operações de "caça não autorizada" realizadas por professores e alunos. É necessário nesse caminhar uma investigação que permita perceber e recuperar os aspectos contraditórios e as diferentes perspectivas postas nesse espaço.

As representações constantemente criadas e recriadas na escola, por professores e alunos, a respeito das aulas de EF, por exemplo, não são gestadas de forma estanque, desvinculadas do que ocorre fora da escola, da vida das pessoas além-muro. Os alunos chegam à escola com uma visão prévia do que é a aula de Educação Física, aprendida por meio de experiências anteriores e pelos significados que são atribuídos a essa disciplina escolar no núcleo familiar, na comunidade, na mídia etc. A escola, por sua vez, a depender de seus outros atores sociais - gestores, professores e funcionários, pode atribuir às aulas de EF diferentes significados, assim, são os pontos de vista semelhantes ou diferenciados com relação ao que é a aula de EF e o que ela significa que vão compor o cenário ao qual a aula de EF é o "palco" das representações.

Certeau (2011b), ao falar das representações aceitas por determinado grupo, afirma que, quando são aceitas, também inauguram uma nova credibilidade, ao mesmo tempo em que a exprimem. A organização dos espaços, tempos, e modos de fazer da escola caminham nessa direção, sempre necessitam de uma credibilidade que as legitime perante professores e alunos, com isso, a leitura de como ocorre essa legitimação passa pela leitura de como esses atores sociais constroem a sua visão de mundo.

Uma questão importante para ser pensada no cotidiano das aulas de EF realizadas na escola é a construção do saber escolarizado. Tratar dessa questão pode dar pistas importantes sobre as maneiras de pensar dos alunos, não apenas em relação à EF, mas à escola, ao conhecimento e à importância desses em suas vidas. 


\title{
O Saber Escolarizado ${ }^{3}$ e as Aulas de Educação Física
}

Clifford Geertz (2012), em sua célebre obra "A interpretação das culturas", já sinalizava que as formas de saber relacionam o que se vê no lugar onde foi visto, incluindo seus revestimentos e instrumentos ao seu aprendizado, construindo, segundo ele, um sistema de significado simbólico. No caso do processo educativo, que engloba a escolarização em todos os seus aspectos e é determinado pelos fatores sociais, políticos e pedagógicos, uma analogia a isso pode ser realizada, uma vez que as formas de saber construídas por um grupo passam por sistemas de significação simbólica que estão presentes tanto na escola como na sociedade, sejam elas conscientes ou não.

Em virtude disso, as pessoas elaboram o que Gusmão (2003) denomina de saber particular, que é construído a partir da observação do mundo onde elas vivem, fruto do agir em sociedade e das experiências vividas com aqueles com os quais se partilha a vida. Essa observação e as experiências vividas a que a autora se refere fazem que os alunos escolham o que é significativo a eles em termos de conhecimento.

A relação com o professor, o interesse ou não em prestar o vestibular, o grau de importância que a disciplina tem tradicionalmente, entre outros, determinam, em grande parte, que tipo de conhecimento terá mais ou menos valor para eles. No limite, tal situação também pode levar os alunos a se submeterem a um saber que eles não compreendem, abstraindo-os de seu contexto.

Certeau (2012, p. 142) tece algumas críticas às instituições que tentam homogeneizar o que é considerado significativo aos sujeitos. Assim, a escola, como instituição, não escapa a elas. O autor não compartilha da ideia de que uma instituição, seja ela qual for, tenha o direito de definir o que é significativo aos outros. Para ele:

\begin{abstract}
Não há um setor particular na sociedade onde se possa fornecer a todos os outros aquilo que os proverá de significação. Seria restaurar o modelo unitário: uma religião imposta a todos, uma ideologia do Estado, ou "o humanismo" de uma classe colonizadora. Que grupo tem o direito de definir, em lugar dos outros, aquilo que deve ser significativo para eles?
\end{abstract}

Esse cenário possibilita compreender o espaço escolar como um campo de embates e negociações entre uma organização, a oficial do sistema escolar e a trama de inter-relações dos sujeitos que a compõem. Nessa operação cotidiana dos sujeitos, táticas que burlam a intenção de instaurar uma estabilidade são lançadas, produzindo, desse modo, operações que se movimentam. Esse movimento, que é de resistência, faz que o conhecimento veiculado na escola não seja apenas aquele oficial, mas ganha outros ingredientes que se misturam a ele e produzem "novos saberes".

Essa produção de novos saberes pode se dar de muitas formas. No entanto, na visão de Rodrigues Júnior e Silva (2008), é o professor que é o detentor do conhecimento sistematizado, científico, e ao se relacionar com os alunos, partindo de um referencial que tem como

3 Segundo Bombassaro (1992), o saber está relacionado a "ser capaz de", "compreender", "dominar uma técnica", "poder manusear", "poder compreender". Assim como "saber escolarizado" compreende-se como aquilo que é produzido a partir da relação entre professores e alunos, na escola. 
foco o cotidiano, poderá identificar em seus interlocutores escolares a bagagem cultural que os mesmos possuem acerca dos temas tratados, de modo a confrontar suas experiências prévias com o conhecimento sistematizado. Esse movimento de encontro e confronto de conhecimentos poderá levar os sujeitos, envolvidos, alunos e professores a produzir novos saberes referentes aos temas trabalhados na escola. Esses saberes necessariamente trarão implicações para a sua vida social, já que poderão significar o aprendizado de novas habilidades, capacidade de compreender coisas novas, ou ainda, de atribuir novos sentidos aos fatos da vida social.

No caso específico da EF, defendemos um ponto de vista ancorado nos princípios de uma EF Plural (DAOLIO, 1995) de que a relação professores e alunos poderá mobilizar saberes relacionados aos elementos da cultura corporal de movimento (jogo, dança, luta, ginástica, esporte etc. $)^{4}$ e também, com base em Silva e Silva (2012), aos conteúdos do lazer (artísticos, manuais, intelectuais, turístico, físico-esportivo, social), sendo a especificidade da EF os conteúdos físico-esportivos, ${ }^{5}$ de modo que tais aulas poderão ampliar as referências dos alunos com relação às atividades a serem realizadas e desenvolvidas no tempo disponível, ao longo da vida, no sentido de uma educação para o lazer. A educação para o lazer a que nos referimos tem como base os estudos de Marcellino (2013), e um estudo recente sobre as representações e o discurso dos professores de Educação Física $(\mathrm{EF})$ a respeito da interface educação/lazer e como isso influencia a sua prática pedagógica (SOUZA; SILVA, 2019).

Essa forma já relatada, de pensar o cotidiano de professores e alunos na escola, não corresponde à tradição das aulas de EF. Tais aulas são marcadas por uma atitude muitas vezes impositiva dos professores de EF e por um "engessamento" com relação ao que será tratado na aula, no sentido de que Certeau (2012) se refere a homogeneizar o que é significativo aos alunos. Assim, é frequente identificar alunos que gostam das aulas de EF e alunos que "odeiam" essas aulas. Em geral, os que gostam das aulas têm experiências bem-sucedidas nas mesmas e o que é proposto pelo professor vai ao encontro do que é esperado por esses alunos de uma aula de EF. Ao contrário, os alunos que "odeiam" tais aulas ficam à margem da quadra, são com frequência os "menos habilidosos", isso devido ao fato de serem desconsiderados os aspectos simbólicos atribuídos às aulas e a seus conteúdos vivenciados, assim como as diferenças entre os alunos.

A escola lida com padrões culturais, sistemas e significados criados historicamente. Entretanto, essa relação tem se dado, na maioria das vezes, conforme afirma Cortella (2013, p. 48-49):

4 Embora o autor em sua obra datada de 1995 se refira ao conceito de "cultura corporal", a partir de sua publicação de 2004 ele passa a adotar o termo "cultura corporal de movimento" por avaliá-lo como sendo mais específico da EF e mais apropriado para tratar as questões simbólicas: "Acredito também que a utilização de um conceito mais simbólico de cultura corporal de movimento propiciará à educação física a capacidade de convivência com a diversidade de manifestações corporais humanas e o reconhecimento das diferenças a elas inerentes" (DAOLIO, 2004, p. 71).

5 Temos aqui também a referência para essa afirmação os estudos de Pires (2008, p. 4): "De forma bastante sintética, podemos afirmar que, embora a Educação Física trate predominantemente de uma especificidade do lazer (os interesses físico-esportivos), ela não deve limitar a esse campo os objetivos e propósitos da sua ação sociocultural". 
[...] de forma que os valores e conhecimentos que atendem aos interesses de grupos sociais que estão situados em posição de predominância na sociedade, [...] acabam por ser difundidos e aceitos pela maioria como se fossem próprios, isto é, travestem-se de um caráter de universalidade.

Todo esse emaranhado de problemas fez emergir na escola algumas contradições, entre elas, a ligada aos grupos que foram sendo estabelecidos nesse espaço. Tal descompasso ocorreu porque esses grupos historicamente tentaram justificar, com base em seus discursos, a importância da sua matéria, importância essa que não tem como base, na maioria das vezes, uma preocupação social, mas interesses corporativos e seccionados. Essa disputa, que pode ser considerada ideológica, espelha, por intermédio do currículo, o conflito de interesses de uma sociedade (SACRISTÁN, 2000).

Também merece destaque nesta discussão o fato de que a transmissão do conhecimento tem inegavelmente como pressuposto a socialização do que foi produzido culturalmente por um grupo, formando o que pode ser identificado, nas discussões realizadas por Certeau (2012), como sendo parte integrante das práticas culturais dos sujeitos. Para o autor, toda cultura requer uma atividade, um modo de apropriação, uma adoção e uma transformação pessoal, um intercâmbio instaurado em um grupo social, uma vez que a cultura não consiste em receber, mas em realizar o ato pelo qual cada um marca aquilo que outros lhe dão para viver e pensar. Sendo assim, o conteúdo cultural é a condição lógica do ensino e, conforme Sacristán (2000), "é muito importante analisar como esse projeto de cultura escolarizada se concretiza nas condições escolares" (p. 30).

Outro ponto importante nessa discussão é a tarefa de regular a vida social, atribuída aos professores pela escola, pois ela legitima a inculcação na criança dos requisitos necessários ao convívio nessa sociedade. Tal estratégia possibilita, por sua vez, atender aos interesses da sociedade em termos de "formação social". Com isso, a prática pedagógica passa, no entender de Gusmão (2003, p. 201), a universalizar a prática cotidiana, que acaba sendo "negada em nome de um ser, que a escola assume como modelo único e uniforme da realidade social".

Todavia, nessa formação social está embutida uma série de fatores, entre eles, um dos mais importantes, é a forma como a sociedade lida com o conhecimento que não foi sistematizado por meio da escrita, como é o caso da oralidade e das vivências corporais. Não queremos dizer, com isso, que a escrita não mereça atenção, porém o conhecimento não é produzido ou difundido apenas desse modo. Além do mais, as práticas culturais podem, por vezes, burlar essa lógica.

Ao estabelecer uma crítica de como a escrita privilegia os grupos dominantes de determinada sociedade, Certeau (2011b, p. 320) afirma que "a escritura se torna um princípio de hierarquização social que privilegia ontem o burguês, hoje o tecnocrata". Ela funciona, segundo ele, como a lei de uma educação organizada pela classe dominante que pode fazer da linguagem o seu instrumento de produção.

Ressalta-se que a importância da escrita não é obra do acaso, uma vez que ela tem fundamental importância para a cultura dominante, principalmente porque é ela que contribui para legitimar o poder, já que a população, pobre e desprovida do acesso à escola, demorou também a ter acesso à escrita. Assim, a estratégia escolhida foi muito eficiente, visto que, 
ao desconsiderar a oralidade, essa população perdia também a possibilidade de participar do processo decisório.

Gusmão (2003, p. 201), ao estabelecer outra crítica, dessa vez sobre como é estabelecida a relação entre a escrita e a oralidade, afirma que:

[...] o mundo moderno, por não reconhecer um saber que se faz fora da escola e da escrita, um saber que considera a experiência do indivíduo como tal e como sujeito coletivo, que tem na oralidade sua maior expressão, não reconhece a diversidade de saberes socialmente produzidos e desconhece as lógicas através das quais o real é percebido, compreendido e representado.

Essas críticas apontadas nos levam a compreender por que as aulas de EF não são tão valorizadas pelos atores sociais na escola. Como essa disciplina trata dos conhecimentos relacionados ao corpo e às práticas corporais, culturalmente dá-se menos importância a esses conhecimentos, ainda que as manifestações corporais possam ser entendidas como diferentes formas de linguagem, expressas pelo corpo. O saber ler e escrever é um conhecimento predominante sobre outros na vida escolar. Essa reflexão explica, de certo modo, a marginalidade das aulas de EF no âmbito escolar, somados a outros significados que circulam sobre tais aulas, envolvendo problemas, como já mencionamos, de ordem didático-metodológica e de organização curricular; problemas que levam alguns alunos a não participarem das aulas como a predominância de atividades lúdicas no ensino primário que perde espaço, nos anos seguintes, para conteúdos esportivizados, fazendo que os alunos "menos habilidosos" percam interesse pelas aulas; situações de exclusão vivenciadas durante as aulas de EF são determinantes para que ocorra o afastamento dos alunos das aulas (TENÓRIO; SILVA, 2017).

Todo esse debate fez que, ao nos depararmos com a organização dessas ideias, surgisse a possibilidade de pensar que um dos objetivos da socialização, que ocorre por meio do processo de escolarização, também pode ser o de propiciar ao indivíduo socializado a participação ativa na sociedade, interferindo, dessa forma, nas condições em que ela acontece, modificando, portanto, a própria sociedade.

Embora esse pensamento pareça de certa forma, óbvio, ele não se materializa atualmente na prática escolar, uma vez que, na maioria dos casos, a escola não tem favorecido uma apropriação crítica dos conteúdos por parte dos alunos.

Outro dado relevante sobre a questão da educação, mas em relação ao processo cultural, é que as relações sociais ao serem vividas, fornecem ao olhar e à nossa percepção esquemas de valores que norteiam as ações e as atitudes de uns sobre os outros, fazendo que a cultura opere como uma rede simbólica que toma por base a experiência humana. Essa relação nos leva a pensar "a cultura no plural" (CERTEAU, 2012). Nessa concepção, os seres humanos passariam, a partir do processo educacional, a se apropriar da produção histórica da humanidade e não apenas de saberes (conhecimentos) escolhidos como válidos por um grupo hegemônico.

Com isso, passaríamos a falar de "culturas no plural", não mais no singular, como comumente essa percepção se apresenta, o que pode contribuir de forma substancial para a compreensão das práticas cotidianas que ocorrem nas aulas de EF na escola, uma vez que elas também estão umedecidas das práticas sociais que influenciam os sujeitos escolares. 
Nessa mesma linha de pensamento, podemos afirmar que, na escola, a produção histórica da humanidade, que é fruto da experiência humana, é sistematizada e se transforma em saber "estruturado", que é considerado assim porque é organizado conceitualmente por meio de uma rede de interconexões e possui uma linguagem própria que garante sua comunicação e possibilita ao professor organizar seu discurso.

O professor, por sua vez, ao organizar seu discurso, é influenciado por uma série de fatores. Desse modo, ao atuar na escola, ele necessita perceber que não é envolvido apenas pela cultura geral. Ele é igualmente envolvido pelo que Penin (1994) denomina de cultura escolar, uma vez que a escola cria ou produz, ela própria, um saber específico, considerando, de um lado, a confrontação entre os conhecimentos sistematizados disponíveis na cultura geral e, de outro, aqueles menos elaborados, provenientes tanto da "lógica" institucional quanto das características da profissão, como ainda da vida cotidiana escolar.

Ao perceber a necessidade e importância disso, o professor se transforma de coadjuvante no processo educacional em protagonista, contribuindo para instaurar uma inquietude e curiosidade nos alunos, necessárias a quem pretende transformar a sociedade em que vive.

Conclui-se com esta discussão que o processo de construção dos saberes e conhecimentos se dá, basicamente, pelas concepções que as pessoas vão acumulando sobre o que é o ensino, e isso ocorre com base no conhecimento sistematizado a ser acessado pelos alunos na escola. No entanto, entre essa percepção e a ação propriamente dita, ocorre uma mediação com o contexto histórico, estabelecendo significados à vida e ao que se acredita fazer parte dela. Nessa interface entre o vivido e aquilo que se acredita viver, temos a noção de historicidade humana que, no limite, determina o que é significativo e, portanto, sistematizado e levado para a escola.

Com isso, a escola passa a ser compreendida não como um lugar de exclusão dos saberes, mas como um espaço que possibilita a troca de experiências, que compreende que as ações realizadas por ela não são neutras, mas, filiadas social e particularmente a determinada cultura.

Considerada essa especificidade, reconhecemos que o pensamento humano é construído socialmente e, de acordo com Geertz (2012, p. 225), ele é "social em sua origem, em suas funções, social em suas formas, social em suas aplicações. Fundamentalmente, é uma atividade pública - seu habitat natural é o pátio da casa, o local do mercado e a praça da cidade". Tomamos a liberdade aqui, de acrescentar às ideias do autor, que esse pensamento humano, igualmente, é construído na escola.

Assim, ao pensarmos os conteúdos que são tratados nas aulas de EF, pode-se considerar que há uma construção cultural de que a aula de EF precisa ser, de certo modo, centrada em sua tradição e quando ela é diferente disso, pode significar um esvaziamento de conteúdos ou uma não aula, o que contribui para que alguns alunos gostem das aulas e outros, ao invés disso, a "odeiem". Diante dos achados neste trabalho, as possíveis justificativas para os alunos não gostarem das aulas envolvem questões relacionadas ao modo como a aula é dada, o modo de tratamento do conteúdo tratado, o tipo de conteúdo e a sua organização/sistematização, a não consideração das diferenças entre os alunos, a não consideração dos aspectos simbólicos que os alunos atribuem às aulas e a seus conteúdos vivenciados, culminando em problemas que podem levar os alunos a se afastarem das aulas de EF e da 
escola. Ao identificar esses achados, as visões de EF que procuram fazer um contraponto ou colocar em discussão seu modo tradicional de aulas (aqui destacamos os estudos de Daolio [1995] e Daolio [2004]), considerando a cultura e sua rede de significados como um elemento fundamental na apropriação de conhecimentos, podem ser uma saída para minimizar os problemas relacionados às aulas de $\mathrm{EF}$ aqui apresentados e tornar essas aulas não somente mais atrativas e interessantes aos alunos, mas reconhecidas por seu valor como conhecimento que é patrimônio da humanidade a ser ensinado na escola.

\section{Cotidiano, Saber Escolarizado e a Ressignificação das Aulas de Educa- ção Física}

Quando nos propomos a refletir sobre como o cotidiano escolar de professores e alunos de EF é constituído, temos de nos remeter, necessariamente, a como esses sujeitos constroem os seus significados a respeito das aulas de $\mathrm{EF}$ e, a partir disso, como é construída as suas relações com a escola, e com os demais atores sociais que compartilham desse mesmo lugar.

As "artes de fazer" dos professores podem se configurar em pistas, que no limite, nos levarão a uma compreensão dos significados presentes em suas práticas cotidianas. A escola é permeada por questões que se tornam intervenientes na medida em que umedecem de significados os sujeitos que nela circulam. Porém, estabelecer conexões entre as relações estabelecidas fora da escola, durante o processo de construção do ser professor, como a formação, a influência da mídia, da família, dos amigos e da comunidade, torna-se essencial para desvelar os significados presentes em suas práticas. Embora tais relações não se estabeleçam isoladamente, cada uma delas influencia em maior ou menor grau a construção do que se pensa e se faz durante a prática pedagógica. A esse respeito, Certeau (2011b) afirma que não há voz pura, uma vez que ela é sempre constituída por um sistema (familiar, social, midiático, econômico etc.). Com isso, não podemos mais falar de uma prática, e sim de práticas sociais.

Associadas às questões já elencadas, acrescentamos que os diferentes interesses e significados atribuídos às aulas de EF refletem em parte, o papel socialmente atribuído a cada membro da sociedade e a sua influência a respeito da construção do significado dessa prática. Segundo Mauss (2015), é em virtude do prestígio que cada um exerce sobre o outro que as ações se tornam significativas. Podemos citar como exemplo o ambiente familiar. Nele, desde os tipos de brinquedo que os filhos recebem de presente quando nascem, passando pelas brincadeiras infantis que meninos e meninas participam, chegando, inclusive, às atribuições domésticas e ao que seus pais pensam acerca das aulas, demarcam atitudes, gostos e sentimentos a respeito das relações com o seu corpo e, por conseguinte, sobre como pensam as aulas de EF.

A respeito da formação dos professores, vários fatores se tornam preponderantes. Ao chegar ao ensino superior, os futuros professores carregam consigo um cabedal de informações, por vezes distorcidas, sobre o que é a EF e, infelizmente, durante a sua formação, elas não são devidamente discutidas. Após terminarem os seus cursos de formação, esses jovens professores ingressam na escola e reproduzem uma concepção de área ainda muito enraizada nas concepções biológicas e de rendimento. Tal prática pedagógica associada ao 
que os alunos trazem de seus espaços de convívio cotidiano estabelece um tipo de pensamento acerca do que é a aula de EF na escola.

Não estamos discutindo aqui se essa ou aquela metodologia, ou esse ou aquele conteúdo é o mais adequado, mas sim, o que se espera do conteúdo da EF na escola. Importa discutir se as aulas de EF reproduzem o modelo de corpo ditado pela mídia ou reproduzem o esporte de alto rendimento e, por conseguinte, as práticas realizadas por ele, ou se ela reflete de forma crítica essas práticas, possibilitando aos alunos uma compreensão de como essas concepções são preestabelecidas e concebidas.

As "artes de fazer" dos professores passam por essas questões constantemente, de forma consciente ou não. É por isso que a formação desses profissionais tem uma relação direta com sua prática cotidiana no processo de escolarização. Não estamos propondo com essa discussão a extinção do ensino dos fundamentos das modalidades esportivas, ou da retirada de alguns temas vinculados à questão biológica, ao contrário, esses temas são necessários e fundamentais aos alunos, o que se coloca em xeque aqui, é a forma como isso ocorre.

Podemos dizer que, na perspectiva de Certeau (2011b), a invenção do cotidiano, no qual professores e alunos são protagonistas, se dá graças às "artes de fazer", às "astúcias sutis", e às "táticas de resistência" que vão alterando os objetos e os códigos presentes na escola, estabelecendo desse modo, uma (re)apropriação do espaço e do uso ao jeito de cada um desses sujeitos. Portanto, pensar no cotidiano das aulas de EF e nas ações dos professores implica pensar nas influências externas às escolas. Temas como o esporte, as danças, as lutas, as atividades rítmicas e os jogos estão associados a questões que fogem aos muros da escola. A família, os amigos, a própria escola e as informações advindas da mídia, somados, constroem uma teia de significados que não se esgota naquele momento único da quadra.

Desse modo, ao se centrar nos estudos do cotidiano, o saber escolarizado é construído a partir da relação e da mediação de conhecimentos entre professores e alunos, que consigo trazem toda uma bagagem de significados atribuídos aos temas referentes às aulas de EF. Certeau (2012) alerta que a polivalência da sociedade penetra nas escolas, apesar das barreiras ou a despeito dos hábitos tricentenários. Com isso, as "artes de fazer" presentes durante as aulas estão diretamente ligadas às resistências que ocorrem no cotidiano da escola, e elas têm uma relação direta com as disputas por um lugar, lugar esse, que, segundo o autor, é praticado e vivido por meio de táticas de resistência que buscam contrariar a reprodução.

Se levarmos em conta esse pensamento, podemos afirmar que o cotidiano dos alunos na escola pode ser um espaço rico em termos de pluralização e, sobretudo, que se constrói pelo uso, também ordinário da multiplicidade de diferenças. Se o cotidiano dos professores está intimamente ligado com o dos alunos, é necessário falar dessa relação quando nos referimos às questões do dia a dia escolar. Não é possível falar das relações estabelecidas em um cotidiano sem relacionar os sujeitos que nele habitam.

Durante uma pesquisa realizada em uma escola da Zona Leste de São Paulo (SOUZA, 2008), foi possível observar a interligação entre todos os setores da unidade escolar (secretaria, sala dos professores, cozinha etc.). Por exemplo, na cozinha se falava das aulas de EF, como se as pessoas que estavam ali tivessem assistido às aulas, comentavam o que os alunos diziam sobre as aulas e também comentavam a respeito dos professores, não só dos de EF. A "inspetora de alunos", na referida pesquisa, demonstrava ter mais domínio das 
coisas da escola do que qualquer pessoa. Ela sabia quais professores eram mais próximos dos alunos e quais deles, segundo sua opinião, eram os melhores professores. Com frequência, os professores solicitavam o seu auxílio para controlar um aluno "problema".

Esses exemplos demonstram o quanto o fazer do professor não é isolado, o quanto ele é carregado de significados que ultrapassam a quadra, que se constroem tanto fora dos muros da escola, como dentro deles, por diversos sujeitos. Sendo assim, reforçamos nosso pensamento de que para compreender o cotidiano das aulas de Educação Física é necessário fazer conexões onde antes não existiam.

Assim, ao final dessas reflexões que aqui apresentamos, consideramos que o cotidiano de professores e alunos está permeado por uma série de relações que envolvem os atores sociais da escola e também os que estão fora da escola. A aula de EF tem a especificidade de lidar com as questões relacionadas ao corpo e à cultura corporal de movimento, assim, essa disciplina escolar poderá se tornar mais significativa para alunos e professores à medida que os novos saberes escolares forem provenientes da relação estabelecida pelos sujeitos envolvidos, com o compromisso de se identificar o que os alunos conhecem sobre os temas tratados e confrontá-los com o conhecimento sistematizado, dando assim, oportunidade para a produção de novos significados atribuídos ao corpo, às práticas corporais, às aulas de EF, em um contínuo processo de ressignificação. Para isso, é fundamental que os professores de $\mathrm{EF}$ ou futuros professores se apropriem das teorias de EF, das abordagens teórico-metodológicas já produzidas pela área e de seu debate, que é o conhecimento sistematizado de seu campo de atuação, para que possam se guiar não somente por suas experiências vividas, pautadas na tradição da EF ou na aula sem especificidade de conhecimentos ou simplesmente em uma não aula. Nesse processo, é fundamental a consideração de que a EF é uma prática pedagógica que necessita de bases teóricas que proponham um novo olhar para a área, contrapondo a visão tradicional e os problemas que mencionamos relacionados à aula de EF, gerando assim, uma representação positiva de tal disciplina escolar para os seus atores sociais. Desse modo, a EF poderá viabilizar aos sujeitos o acesso a conhecimentos que são patrimônio da humanidade, como o jogo, a ginástica, o esporte, a dança, a luta etc. e o seu trato pautado no respeito às diferenças e particularidades dos sujeitos e do meio onde vivem. Essa talvez seja a forma mais eficaz de resistência à tradição das aulas de EF e aos problemas que ocasionam exclusão e evasão dos alunos das atividades propostas.

Assim, chegamos a um esquema explicativo do ponto de vista que procuramos aqui apresentar: 


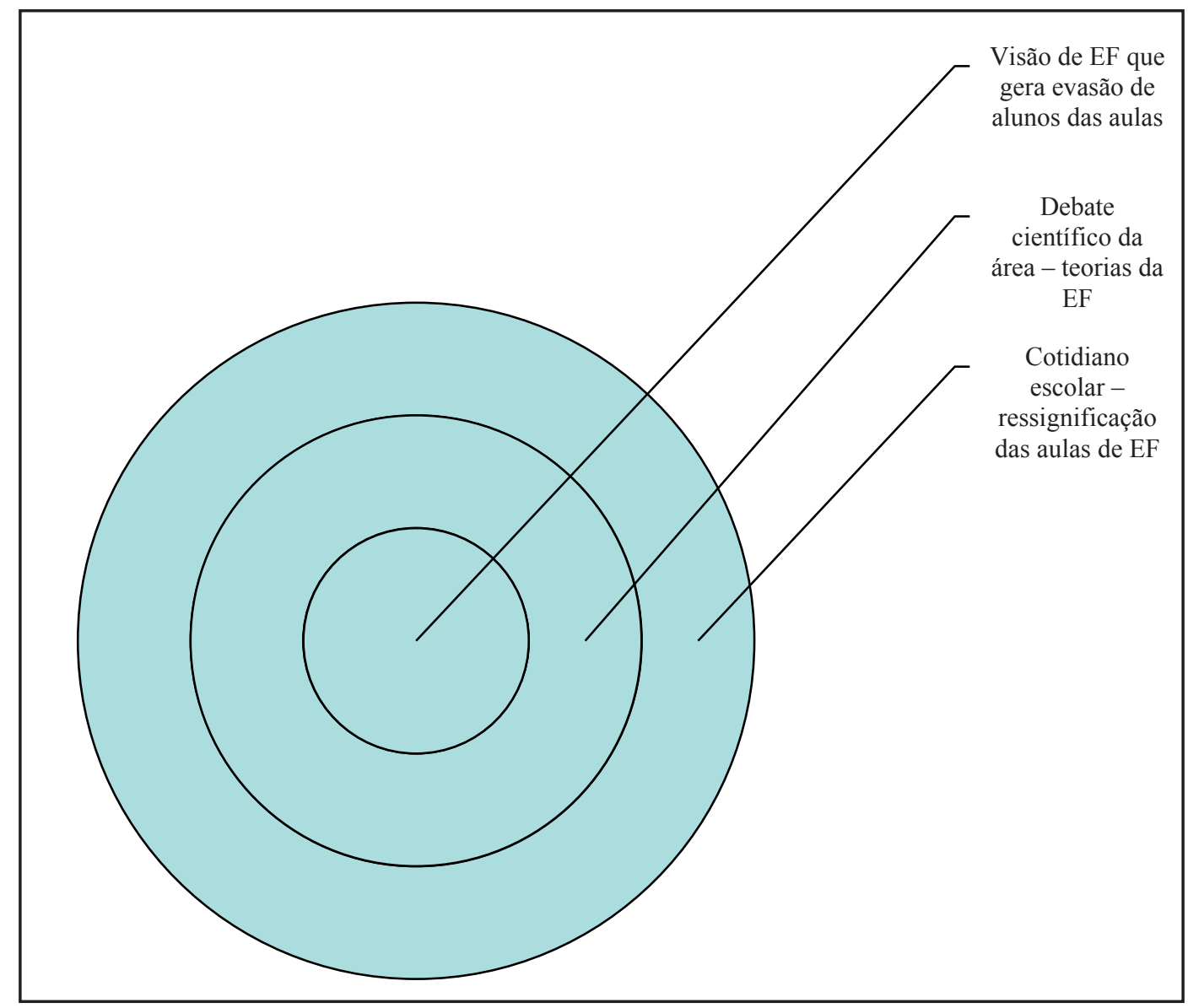

Fonte: Elaborado pelos autores.

\section{CONSIDERAÇões FINAIS}

Afirmamos no início que a escola e os acontecimentos que permeiam o seu cotidiano se dão a partir das relações sociais estabelecidas entre os sujeitos e o mundo em que vivem. Percebemos, também, a partir de uma reflexão sobre o tema, que a relação dos professores de EF com a escola, e por conseguinte com as aulas e seus alunos, deve ser vista como um estar sendo, ela não é dada pronta, é construída cotidianamente e se modifica, na medida em que os sujeitos vão se relacionando. Embora existam padrões preestabelecidos que são influenciados pelos vários fatores já elencados, essa relação se dá e se constrói de diversas formas com os alunos, professores e demais membros da escola.

Portanto, as maneiras de pensar de professores e alunos estão vinculadas a uma lógica complexa na sua essência, e se queremos compreendê-la, devemos penetrar nesse universo com a humildade de quem está sempre aprendendo, só assim poderemos estabelecer as conexões dos fios que compõem essa teia de significados, como já bem dizia Geertz (2012).

Devemos lembrar que os sujeitos inventam novas artes de fazer a todo o momento, seja na escola ou fora dela. Não menos importante que isso, é necessário perceber que 
sempre surgem novas táticas de resistência desse lugar habitado, praticado e vivido (CERTEAU, 2011b). Sendo assim, o cotidiano de professores e alunos na escola é construído e reconstruído de forma dialética, não há um aspecto único que o influencia. É justamente o contínuo processo de ressignificação das aulas, pautado nos conhecimentos sistematizados produzidos pela área, que pode gerar a resistência à tradição das aulas de EF e minimizar problemas que afastam os alunos das aulas de EF e da escola.

\section{REFERÊNCIAS}

BETTI, M., LIZ., M. T. F. Educação Física escolar: a perspectiva de alunas do ensino fundamental. Motriz, v. 9, n. 3, p. 135-142, 2003.

BOMBASSARO, L. C. As fronteiras da epistemologia: como se produz o conhecimento, 2. ed. Petrópolis: Vozes, 1992.

BRACHT, V. Cenas de um casamento (in)feliz. Rev. Bras. Cienc. Esporte, v. 22, n. 1, p. $53-63,2000$.

BRASIL. Recuperado em 02 dezembro, 2016, de http://www.todospelaeducacao.org.br/ reportagens-tpe/32163/apenas-543-dos-jovens-concluem-o-ensino-medio-ate-os-19-anos/. 2014.

BRASIL. Instituto Brasileiro de Geografia e Estatística. Recuperado em 02 dezembro, 2016, de http://www.ibge.gov.br/home/estatistica/indicadores/trabalhoerendimento/pnad continua/primeiros_resultados/analise 02.shtm. 2016.

CERTEAU, M. de. A escrita da história, 3. ed. Rio de Janeiro: Forense, 2011a.

. A invenção do cotidiano: vol. 1, Artes de fazer, 20. ed. Petrópolis: Vozes, 2011 b.

. A cultura no plural, 7. ed. Campinas: Papirus, 2012.

CHIZZOTTI, A. O cotidiano e as pesquisas em educação. In: FAZENDA, I. C. A. (org.). Novos enfoques da pesquisa educacional, 7. ed. São Paulo: Cortez, 2010.

COLETIVO DE AUTORES. Metodologia do ensino de Educação Física. São Paulo: Cortez, 1992.

CORTELLA, M. S. A escola e o conhecimento: fundamentos epistemológicos e políticos, 14. ed. São Paulo: Cortez, 2013.

DAOLIO, J. Por uma educação física plural. Motriz, v. 1, n. 2, 134-136, 1995. 
. Educação Física e o conceito de cultura. Campinas: Autores Associados, 2004.

. Da cultura do corpo, 17. ed. Campinas: Papirus, 2013.

DAYRELL, J. A escola como espaço sócio-cultural. In: DAYRELL, J. (org.). Múltiplos Olhares sobre educação e cultura. Belo Horizonte: UFMG, 1996.

FREIRE, J. B., SANTANA, G. M. L. Relações sociais no desenvolvimento da imaginação por meio de jogos. Motriz, v. 13, n. 4, p. 249-258, 2007.

GEERTZ, C. A interpretação das culturas. Rio de Janeiro: LTC, 2012.

GUSMÃO, N. M. M. Antropologia, processo educativo e oralidade: um ensaio reflexivo. Pro-posições, v. 14, n. 1, p. 197-213, 2003.

MARCELLINO, N. C. Lazer e educação, 17. ed. Campinas, 2013.

MAUSS, M. Sociologia e Antropologia, 2. ed. São Paulo: Cosac Naify, 2015.

PENIN, S. T. de S. A aula: espaço de conhecimento, lugar de cultura. Campinas: Papirus, 1994.

PIRES, G. de L. Lazer e desenvolvimento pessoal e social. Anais do IX Seminário Lazer em Debate. USP/Leste - Celar/UFMG, São Paulo, p. 4. Recuperado em 06 de julho, 2020, de file://C:/Users/cinth/Downloads/19pires_2008.pdf, 2008.

RODRIGUES JÚNIOR, J. C., SILVA, C. L. da. A significação nas aulas de educação física: encontro e confronto dos diferentes "subúrbios" de conhecimento. Pro-posições, v. 19, n. 1, p. 159-172, 2008.

SACRISTÁN, J. G. O currículo: uma reflexão sobre a prática, 3. ed. Porto Alegre: ArtMed, 2000.

SILVA, C. L. da, SILVA, T. P. Lazer e educação física: textos didáticos para a formação de profissionais do lazer. Campinas, SP: Papirus, 2012.

SILVA. R. A., et al. Fatores motivacionais para a prática de Educação Física em alunos de uma escola pública. Extensão, v. 2, n. 1, p. 36-41, 2018.

SOUZA, A. S. Educação Física no Ensino Médio: representações dos alunos. Tese de Doutorado Não-Publicada, Programa de Pós-Graduação em Educação Física, Universidade Estadual de Campinas, Campinas-SP, 2008. 
SOUZA, A. dos S., SILVA, C. L. da. A interface educação/lazer: representações e discursos de professores de Educação Física da rede pública de Piracicaba-SP. Licere, v. 22, n. 3, p. 1-33, 2019.

TENÓRIO, J. G., SILVA, C. L. da. As razões da não participação de alunos nas aulas de Educação Física do Ensino Fundamental. Rev. Bras. Educ. Fís. Escolar, Ano III, v. 1, p. 73-87, 2017.

TENÓRIO, J. G., SILVA, C. L. da. O desinteresse dos estudantes pelas aulas de Educação Física em uma escola de ensino público do estado de Mato Grosso. Salusvita, v. 34, n. 1, p. 27-44, 2015.

WITTIZORECKI, E. S., MOLINA NETO, V. O trabalho docente dos professores de Educação Física na rede municipal de ensino de Porto Alegre. Movimento, v. 11, n. 1, p. 47-70, 2005.

\section{DADOS DOS AUTORES}

\section{Adalberto dos Santos Souza}

Doutor em Educação Física pela Universidade Estadual de Campinas e Pós-doutorado em Ciências do Movimento Humano pela Universidade Metodista de Piracicaba. Professor associado na Universidade Federal de São Paulo. Guarulhos/SP-Brasil. neysouza11@hotmail.com

\section{Cinthia Lopes da Silva}

Doutora em Educação Física pela Universidade Estadual de Campinas. Professora oo Programa de Pós-graduação em Ciências do Movimento Humano da Universidade Metodista de Piracicaba/SP-Brasil. cinthia.silva@unimep.br

Submetido em: 5-6-2020

Aceito em: 7-7-2020 